\title{
GEOTECNOLOGIAS NO ENSINO DA CARTOGRAFIA ESCOLAR NO PROCESSO ENSINO-APRENDIZAGEM ${ }^{1}$
}

\author{
Odinei Edson Leite Brasil - Bolsista de Extensão - Universidade Federal de Campina \\ Grande - Campus Cajazeiras (CFP-UFCG) \\ odinei1994@hotmail.com
}

\author{
Orientadora: Profa. Dra. Alexsadra Bezerra da Rocha - Universidade Federal de \\ Campina Grande - Campus Cajazeiras (CFP-UFCG) \\ alexsandra.rocha@ufcg.edu.br
}

\section{RESUMO}

\begin{abstract}
A matriz curricular brasileira ainda não apresenta uma disciplina especifica de cartografia escolar que supra a necessidade desta ciência e abrace a demanda das escolas. O objetivo deste trabalho versa relatar algumas experiências no primeiro semestre deste ano (2017) do projeto de extensão: Cartografia e Geotecnologia: Levando o conhecimento cartográfico a escola. Como objetivos específicos: Analisar a aprendizagem dos alunos da Escola Estadual Cidadã Técnica de Cajazeiras - Profa. Nicéia Claudino Pinheiro - PB durante as oficinas da cartografia escolar; Observar o nível de aprendizagem destes alunos com o uso de geotecnologias e ferramentas metodológicas, a partir de aplicativos de celular e programas em computador; Formar 4 alunos da escola, trazendo-os até a universidade para que estes pudessem ter oficinas de forma didática, tais como: Computador, Aplicativo de Celular, Globo, Cartas Topográficas, Mapas, Tabelas, Programa Google Maps e Google Earth Pro, futebol Cartográfico e bussola. Estes alunos participaram da segunda temporada das Olimpíadas de Cartografia Nacional, o grupo conseguiu perceber que mesmo em poucas aulas e tempo, estes alunos puderam absolver melhor o conteúdo trabalhado obtendo um bom resultado nas olimpíadas.
\end{abstract}

PALAVRAS-CHAVE: Cartografia. Geotecnologia. Extensão

\section{GEOTECHNOLOGIES IN TEACHING SCHOOL CARTOGRAPHY IN THE TEACHING- LEARNING PROCESS}

\begin{abstract}
The Brazilian curricular matrix does not yet present a specific discipline of school cartography that supra the need of this science and embrace the demand of the schools. The objective of this work is to report some experiences in the first semester of this year (2017) of the extension project: Cartography and Geotechnology: Carrying the cartographic knowledge to the school. As specific objectives: To analyze the learning of the students of Cajazeiras State Technical Citizen School - Profa. Nicéia Claudino Pinheiro - PB during the school cartography workshops; To observe the level of learning of these students with the use of geotechnologies and methodological tools, from cellular applications and computer programs; To train 4 students of the school, bringing them to the university so that they could have didactic workshops, such as: Computer, Cellular

1 Este trabalho conta com recurso do PROBEX. Elaborado no Laboratório de Cartografia e Geoprocessamento - UNAGEO/CFP.
\end{abstract}

Revista de Pesquisa Interdisciplinar, Cajazeiras, n. 2, suplementar, p. 22 - p. 28, set. de 2017. 
Application, Globe, Topographic Charts, Escalimetro, Maps, Tables, Google Maps Program and Google Earth Pro, Cartographic football and bussola. These students participated in the second season of the National Cartography Olympics, the group managed to realize that even in a few classes and time, these students could better absolve the content worked getting a good result in the Olympics.

KEY WORDS: Cartography. Geotechnology. Extension

\section{INTRODUÇÃO}

A Cartografia é uma linguagem de comunicação fundamental para o entendimento da organização espacial e muito importante para a compreensão do modo como a sociedade ocupa os espaços e mantém suas relações, sejam elas físicas, políticas, econômicas ou sociais.

No contexto do mundo contemporâneo a educação necessita cada vez mais de inovação, as escolas procuram novas ferramentas metodológicas que facilitem a aprendizagem do alunato. Neste contexto, as geotecnologias surgem com grande potencial na formação discente, conduzindo novas possibilidades na aprendizagem. A princípio, na cartografia essas tecnologias têm uma vasta aplicação. Entretanto, o potencial delas nos estudos cartográficos não tem sido suficientemente explorado. Isto ocorre em grande parte devido à deficiência na formação inicial do professor e à falta de formação continuada essencial para acompanhar os crescentes avanços tecnológicos, bem como as necessidades da escola. Nesse contexto, Melo \& Oliveira (2009) afirmam que as geotecnologias:

São ferramentas de suma importância para o ensino da cartografia escolar, e conforme os autores "facilitam o acesso a todos os mapas imagináveis, políticos, físicos, econômicos, demográficos, com possibilidades ilimitadas de mudança de escala e de passagem a textos explicativos ou a animações" (MELO; OLIVEIRA, 2009 , p. 5)

A julgar pelo fato da matriz curricular brasileira ainda não oferecer uma disciplina específica na educação básica, que supra a necessidade e a demanda existente nas escolas públicas em relação à cartografia, este fato motivou o projeto de extensão: Cartografia e Geotecnologia: Levando o conhecimento cartográfico a escola, apresenta uma proposta de inovação e incentivo a ciência cartográfica nas escolas, com análises e relatos da experiência do uso de geotecnologias no ensino de cartografia no primeiro semestre deste ano (2017).

A proposta abrange um conjunto de ações aspirando ao fortalecimento da função social do curso de Geografia da UNAGEO/CFP, bem como da cidadania dos alunos no exercício do processo de ensino - aprendizagem e aperfeiçoamento do repasse do saber. Neste 
intuito, este projeto infere um repertório de ferramentas metodológicas e de instrumentos didáticos, cujo desenvolvimento tem como base o reconhecimento da ciência no processo de reflexão e interlocução com a realidade social, firmando-se na relação entre teoria e prática na produção do conhecimento em cartografia, fazendo com que o saber científico produzido na academia chegue ao universo da escola.

O projeto de extensão iniciou com uma seleção de 4 alunos na Escola Estadual Cidadã Técnica de Cajazeiras - Profa. Nicéia Claudino Pinheiro - PB que participaram de atividades avaliativas de forma que pudessem ajudar o grupo do projeto na escola no momento da execução das oficinas. A seleção contou com uma prova de múltipla escolha e uma redação sobre cartografia, 60 alunos se inscreveram para participar deste processo de seleção. Os critérios de avaliação foram maior nota, no final 4 alunos foram selecionados.

Figura 1: Momento do Processo Seletivo na Escola

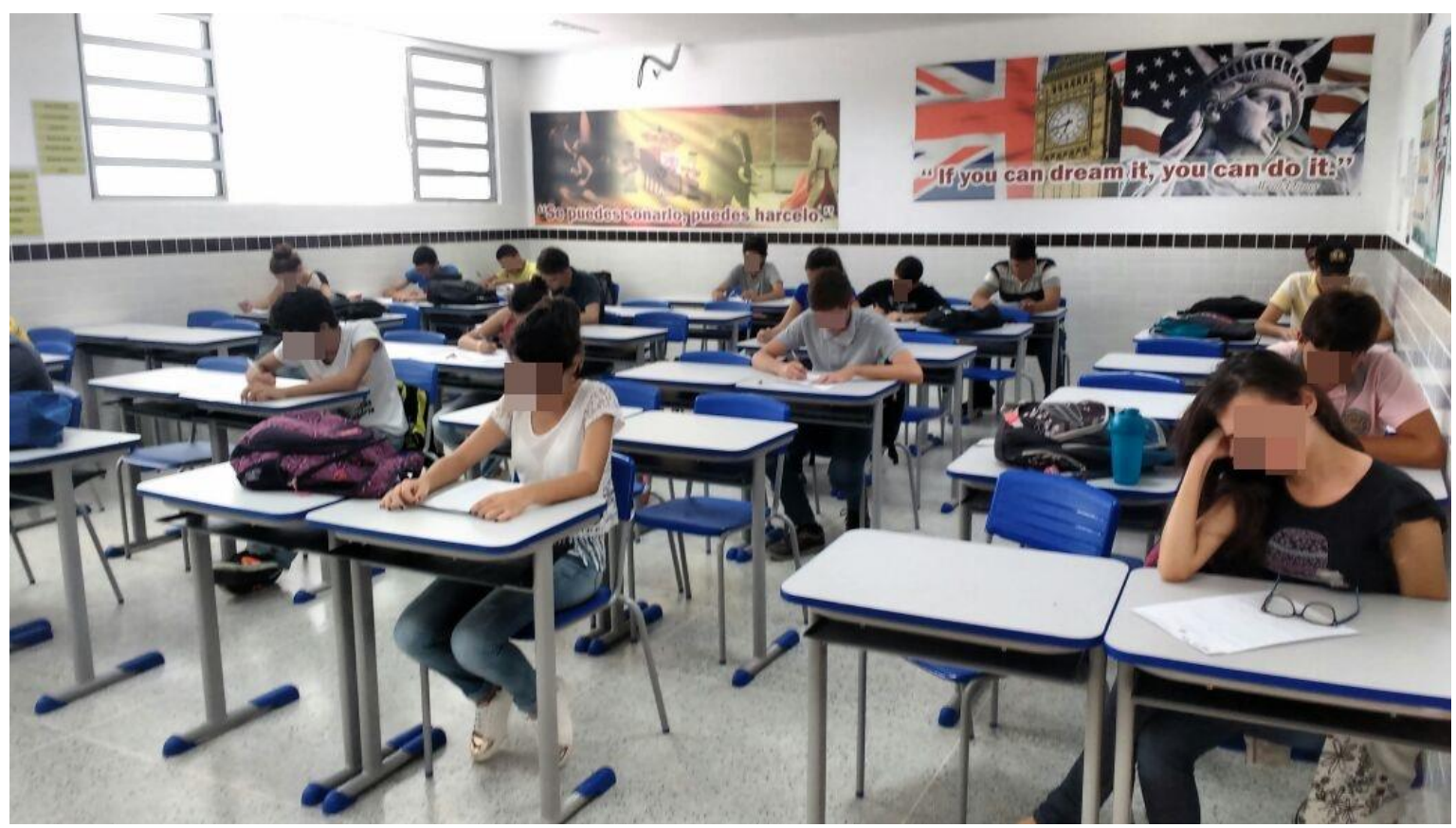

Fonte: Professor da escola

As oficinas para o processo de formação destes alunos foram realizadas na Universidade Federal de Campina Grande - Campus Cajazeiras - PB (CFP-UFCG) no Laboratório de Cartografia e Geoprocessamento - LACARGEO, ocorreram no total 4 oficinas, com os seguintes temas: orientação e localização, latitude e longitude; Escala Cartográfica e Fuso horário. Cada oficina foi realizada de forma didática e com o uso de 
geotecnologias com diferentes propósitos, procurando inovar no ensino e mantendo a essência da ciência Cartográfica.

O principal objetivo deste projeto é: Analisar a aprendizagem dos quatro alunos participantes das oficinas; e como objetivos específicos: Formar os quatro alunos participantes das oficinas, com a utilização de ferramentas Cartográficas; Observar o nível de aprendizagem destes alunos com o uso de geotecnologias e ferramentas metodológicas utilizadas nas oficinas.

A partir do término das oficinas os alunos recém formados participaram da segunda temporada das Olimpíadas de Cartografia $\mathrm{Nacional}^{2}$, as olimpíadas científicas estimulam o conhecimento, propondo aos participantes um desafio construtivo. Podemos perceber nesta etapa do projeto que o grupo de alunos conseguiram resultados significativos, mesmo em poucas aulas e pouco tempo, sendo inclusive uma forma da equipe observar se os conhecimentos repassados de acordo com a metodologia estabelecida atendia aos objetivos do projeto. Os alunos da escola conseguiram absorver melhor o conteúdo trabalhado obtendo resultado bastante significativo na Olimpíada de Cartografia Nacional.

\section{METODOLOGIA}

Este trabalho foi realizado na Universidade Federal de Campina Grande - Campus Cajazeiras - PB (CFP-UFCG) no Laboratório de Cartografia e Geoprocessamento LACARGEO. Teve início com uma seleção na Escola Estadual Cidadã Técnica de Cajazeiras - Profa. Nicéia Claudino Pinheiro - PB, onde 4 alunos foram selecionados. O passo seguinte foi a realização das oficinas, foram realizadas no total quatro oficinas com diferentes temas e finalidades, sendo que em todas, foram utilizadas geotecnologias tais como: Computador, Aplicativo de Celular, Globo, Cartas Topográficas, Mapas, Tabelas, Programa Google Maps e Google Earth Pro, futebol Cartográfico e bússola, Além de um eficaz e inovador método de ensino - aprendizagem baseado na teoria e prática utilizando Geotecnologias disponíveis de forma gratuita e de fácil acesso. Ao final do trabalho os alunos recém formados participaram

A Olimpíada Brasileira de Cartografia (OBRAC) tem como objetivos principais estimular, na escola, o interesse pelas Ciências, especialmente pela Cartografia; prover aos professores o conhecimento e ferramentas para o ensino dinâmico e participativo em áreas que abrangem o conteúdo cartográfico, prover a socialização de professores e alunos através de atividades em equipe e fomentar a formação de recursos humanos para atuação na área de Cartografia e das geotecnologias. Cada escola inscrita participará com uma equipe, de 4 alunos e um professor, o chefe da equipe. A OBRAC será executada em etapas conforme o Regulamento a ser em breve divulgado neste site (http://www.olimpiadadecartografia.uff.br/index.php/menu-vertical2/35-obrac2017). 
da segunda temporada das Olimpíadas de Cartografia Nacional, foi possível identificar que a metodologia usada fez-se eficaz, mesmo em poucas aulas e em um período curto, os alunos participantes das oficinas absolveram melhor o conteúdo que foi trabalhado, alcançando resultado expressivo na Olimpíada de Cartografia Nacional.

\section{RESULTADOS E DISCUSSÕES}

A Primeira oficina foi dividida em três instantes e o tema foi a Escala Cartográfica. Teve início com uma pequena apresentação do conteúdo de forma breve. No segundo, com o auxílio de geotecnologias foi exposto ilustrações em forma de desenho animado para facilitar o entendimento dos alunos, do que foi explicado anteriormente. Para a última parte foi abordado os cálculos e práticas no pantógrafo e na carta topográfica.

Figura 2: Analise de cartas topográficas/Introdução a escala

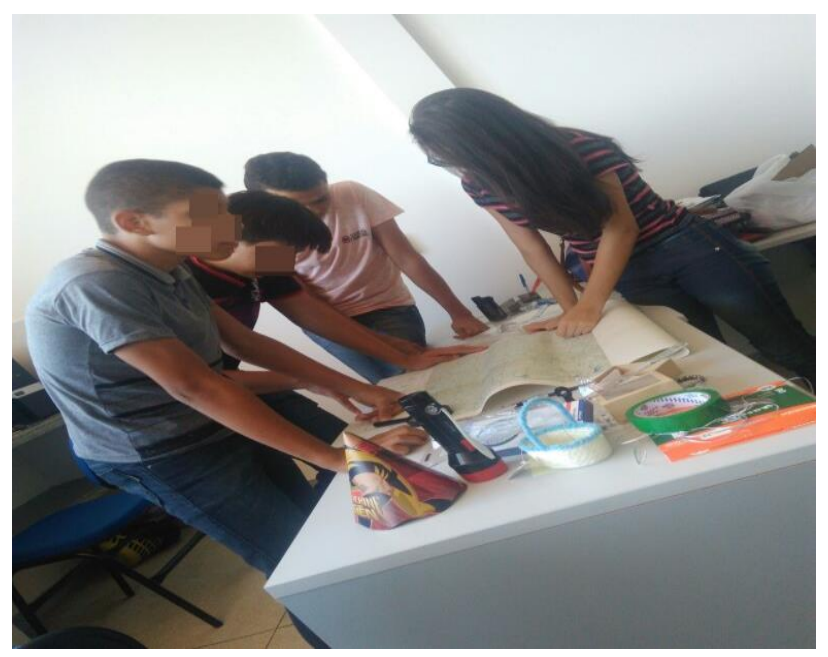

Fonte: Equipe do Projeto

A segunda e terceira oficina realizada foi a de orientação e localização (latitude e longitude), esta oficina esteve dividida em dois momentos. O primeiro momento foi destinado a abordagem de conteúdo. Os assuntos trabalhados foram: Pontos colaterais e subcolaterais, Rumo e Azimute. Logo após os alunos receberam uma bola de isopor e foi solicitado que desenhassem os meridianos e paralelos, conjunto de latitude e longitude. Na parte final com o auxílio do futebol cartográfico, uma forma didática e divertida de trabalhar a orientação, os 
alunos finalizaram a oficina respondendo perguntas a respeito dos pontos cardeais e colaterais.

Figura 3: Aula teórica e prática sobre orientação localização

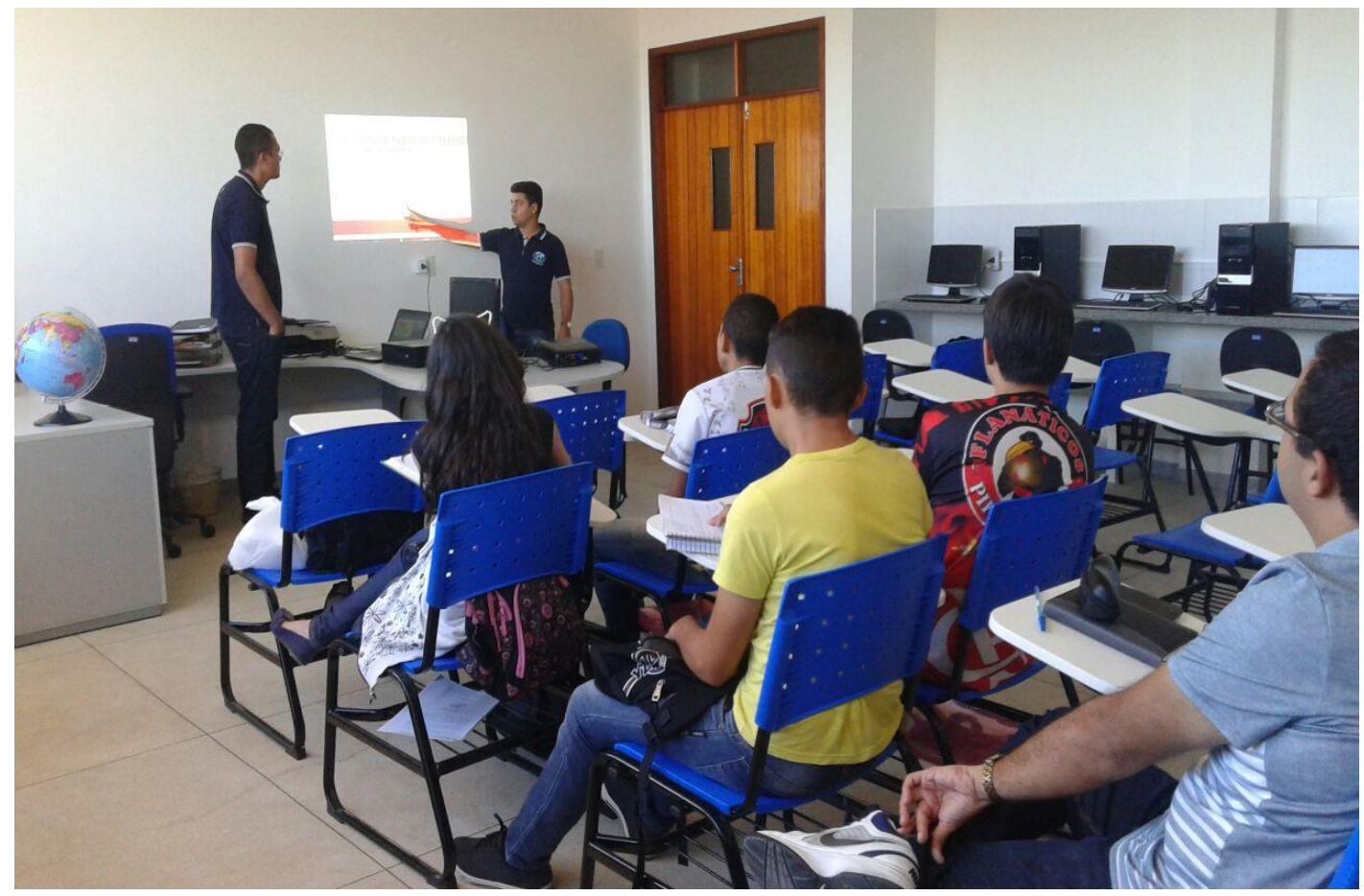

Fonte: Equipe do Projeto

A quarta oficina foi sobre fuso horário. Com três momentos distintos, a oficina na primeira parte fez um resumo de todo o conteúdo já visto, com o auxílio do globo alguns pontos chave foi discutido e revisado, tais como: Meridianos e paralelos, Rotação e Translação, longitude e latitude e por último Fuso Horário. Na segunda parte falou-se sobre fuso horário: Para que serve o fuso horário, tipos de horas, o fuso, linha internacional de mudança de data, como se calcula o fuso horário de diferentes países. Por fim, os alunos responderam um exercício para fixar os conhecimentos, este exercício também serviu como teste para avaliação do que foi proposto durante a oficina.

\section{CONSIDERAÇÕES FINAIS}

O propósito da elaboração do trabalho foi mostra que é possível uma metodologia de ensino diferente e eficaz, com o auxílio de Geotecnologias em relação a ciência Cartografia. 
Tendo em vista, que a matriz curricular brasileira não apresenta uma disciplina específica de Cartografia, fica exposto nesse trabalho que é viável trabalhar a cartografia em sala de aula com Geotecnologias acessíveis para os alunos.

Com isso, apresentamos a importância das Geoetnologias no ensino-aprendizagem da Cartografia, auxiliada por uma didática e metodologia diferenciada. Além do uso da cartografia como meio social, bem como da cidadania dos alunos no exercício do processo de ensino - aprendizagem e aperfeiçoamento do repasse do saber.

Portanto o desenvolvimento do trabalho, a partir das informações obtidas, trouxe um modo especial de ensino, que facilitou a dinâmica das aulas, bem como a aprendizagem dos alunos.

\section{REFERÊNCIAS}

Brasil, Ministério da Educação. Parâmetros Curriculares Nacionais. Geografia (5a a 8a série), SEF, Brasília,1998, $156 \mathrm{p}$

CASTELLAR, S. M. V.; SACRAMENTO, A. C. R.; MUNHOZ, G. B. Recursos Multimídia na Educação Geográfica: perspectivas e possibilidades. Ciência Geográfica, Bauru, v. 15, n. 1, jan./dez. 2011. Disponível em: http://migre.me/bP5Qb. Acesso em: Novembro de 2012.

Di Maio, A, C. Ensinar Cartografia no século XXI: o desafio continua, trabalho apresentado no Colóquio de Cartografia para Escolares, 2013.

Di Maio, A.C.; Santos, Kellen M.G. Uma História de Mapas para contar: a I Olimpíada Brasileira de Cartografia. In: Colóquio de Cartografia para Escolares, Goiânia, 4 a 7 de outubro de 2016. Disponível em: http://media.wix.com/ugd/10c2d1_19939615b2164018bc38913fbf5ef41c.pdf

FRANCISCHETT, M. N. A cartografia escolar crítica. In: ENCONTRO NACIONAL DE PRÁTICA DE ENSINO EM GEOGRAFIA, 2007, Rio de Janeiro. Anais eletrônicos. Rio de Janeiro: 2007. Disponível em http://www.uff.br/enpeg2007. Acesso em: 14 dez. 2015. JOLY, Fernand. A cartografia. São Paulo: Papirus, 1990.

MELO, J. A. B; OLIVEIRA, M. M. Educação geográfica e geotecnologias: Da reprodução à reconstrução do conhecimento na sala de aula. In: ENCONTRO NACIONAL DE PRÁTICA DE ENSINO EM GEOGRAFIA, 10., 2009, Porto Alegre. Anais eletrônicos. Porto Alegre: 2009. Disponível em http://www.agb.org.br/XENPEG/artigos. Acesso em: 01 fev. 2016.

OLIVEIRA, L. de Estudo Metodológico e Cognitivo do Mapa. (Tese de Livre Docência, Universidade Estadual Paulista Júlio de Mesquita Filho), São Paulo, Rio Claro, 1977. OXERA CONSULTING LTD. What is the economic impacto of Geo service? Prepared for Google. Disponível em $<$ http://www.oxera.com/LatestThinking/Publications/Reports/2013/What-is-the-economic-impact-of-Geo-services.aspx >. Acesso em out. 2013

ROSA, R. Geotecnologias na geografia aplicada. Revista do Departamento de Geografia, n. 16, p. 81-90, 2005. 